\title{
Giant Adrenal Pseudocyst Treated Laparoscopically; Case Report and Review of the Literature
}

\author{
Fatima Aloraifi ${ }^{*}$, Gavin O'Brien and Paddy Broe
}

\author{
Department of General Surgery, Beaumont Hospital, Dublin 9, Republic of Ireland
}

\begin{abstract}
We report a case of a giant adrenal pseudocyst, found incidentally in a 45 year old female. Her CT scan showed a $7.5 \mathrm{~cm} \times 7.3 \mathrm{~cm}$ suprarenal mass and she underwent a laparoscopic transperitoneal adrenalectomy. We report this case and review the literature regarding the diagnosis and management of adrenal pseudocysts.
\end{abstract}

\section{CASE REPORT}

A 45 year old housewife with multiple sclerosis was discovered to have a large right suprarenal mass as an incidental finding on a computed tomography (CT) scan of her lumbosacral spine. On close questioning, she reported a vague history of episodes of right flank pain for the previous 2 years. She also described episodes of flushing and lethargy which raised a suspicion of a possible diagnosis of phaeochromocytoma. There was no prior history of trauma or malignancy. The examination was normal other than a palpable mass in the right upper quadrant.

An adrenal protocol CT scan was performed revealing a $7.5 \mathrm{~cm} \times 7.3 \mathrm{~cm}$ suprarenal cystic lesion with a calcified rim (Figs. 1,2). A renal or adrenal origin of the mass was difficult to distinguish. Otherwise, no metastatic disease was seen. The possibility of a phaeochromocytoma was considered, although these tumors normally display enhancement.
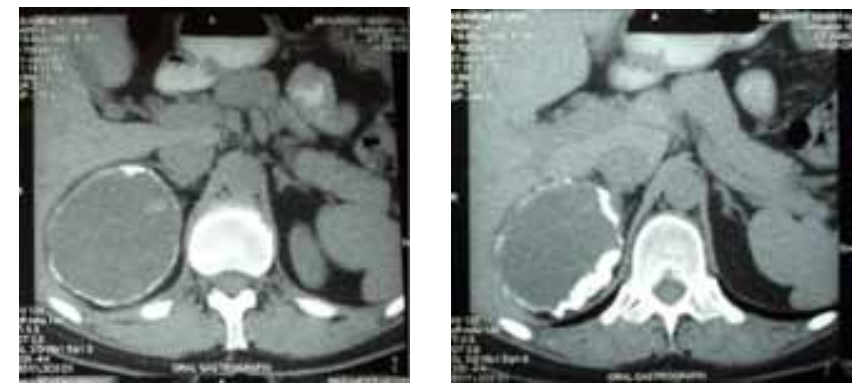

Figs. (1,2). CT abdomen with contrast showing $7.5 \mathrm{~cm} \times 7.3 \mathrm{~cm}$ mass in the supra-renal area. The calcified rim is well depicted here.

Subsequently, functional investigations of the adrenal mass were performed including urinary catecholamines, metanephrines, and 5-HIAA along with serum cortisol, aldosterone and calcium; all were within normal limits. Therefore if it was an adrenal mass, it was hormonally inactive. Given its large size, its potential malignancy and the hazards involved in biopsying a cystic lesion of unknown aetiology, a decision was made to excise the mass surgically.

We proceeded to perform a laparoscopic transperitoneal right adrenalectomy. The patient was placed in the lateral

*Address correspondence to this author at the Department of General Surgery, Beaumont Hospital, Dublin 9, Republic of Ireland;

E-mail; 3raifi@gmail.com decubitus position. Following camera insertion (verres technique) in the anterior axillary line, three $5 \mathrm{~mm}$ trocars were positioned along the right subcostal margin (Fig. 3). The large supra-renal cyst was intimately adherent to and arising from the right adrenal gland. A clean tissue plane existed between the mass and the right kidney. Careful dissection of that plane and medial retraction of the IVC allowed the identification of the right adrenal vein, which was clipped with titanium clips and divided. Further haemostatic dissection was achieved with a harmonic scalpel (Ethicon Endo-Surgery, USA). The adrenal gland and the mass were then mobilized, excised en-bloc and sent for histology for further evaluation.

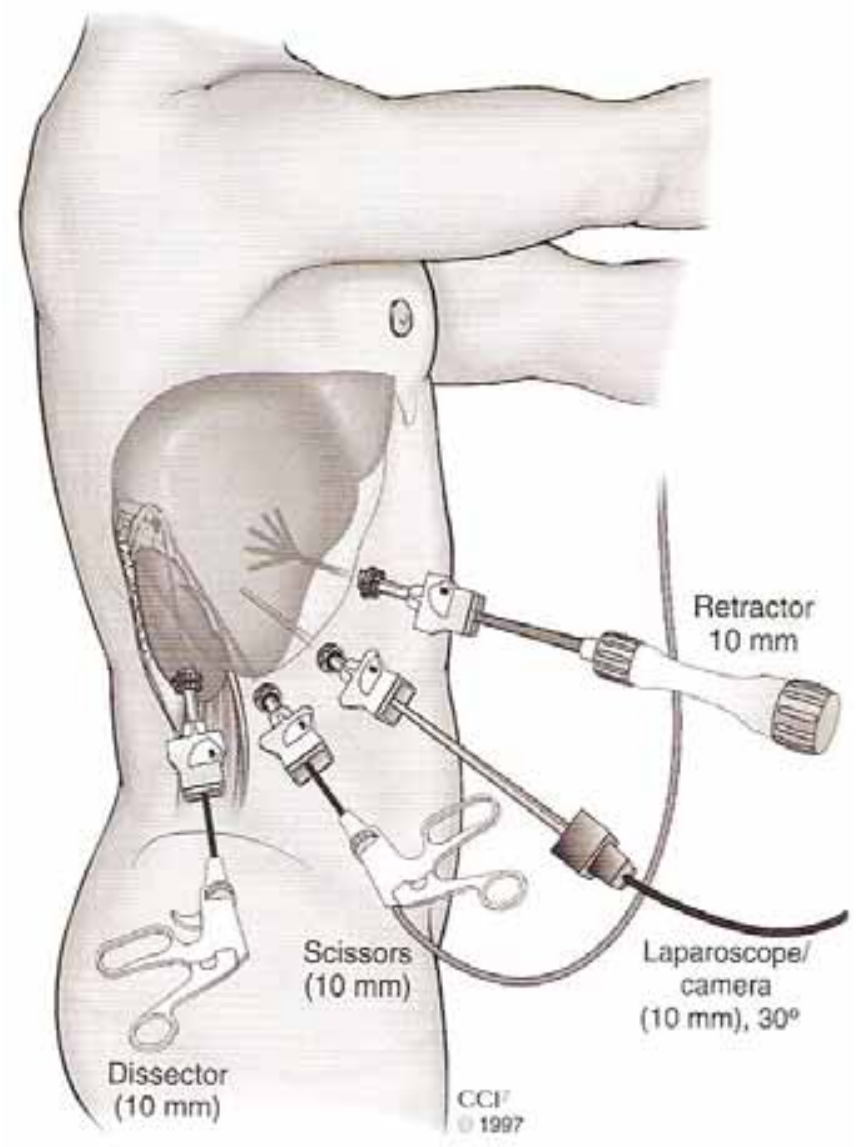

Fig. (3). Position of trocars for laparoscopic transabdominal right adrenalectomy [1].

2008 Bentham Open 
The cystic structure measured $8 \mathrm{~cm} \times 8 \mathrm{~cm} \times 1.5 \mathrm{~cm}$ (Fig. 4). Opening of the cyst revealed a cream, smooth walled inner surface filled with soft creamy material. There was also a firm calcified area measuring $3 \mathrm{~cm} \times 2.5 \mathrm{~cm} \times 1 \mathrm{~cm}$.

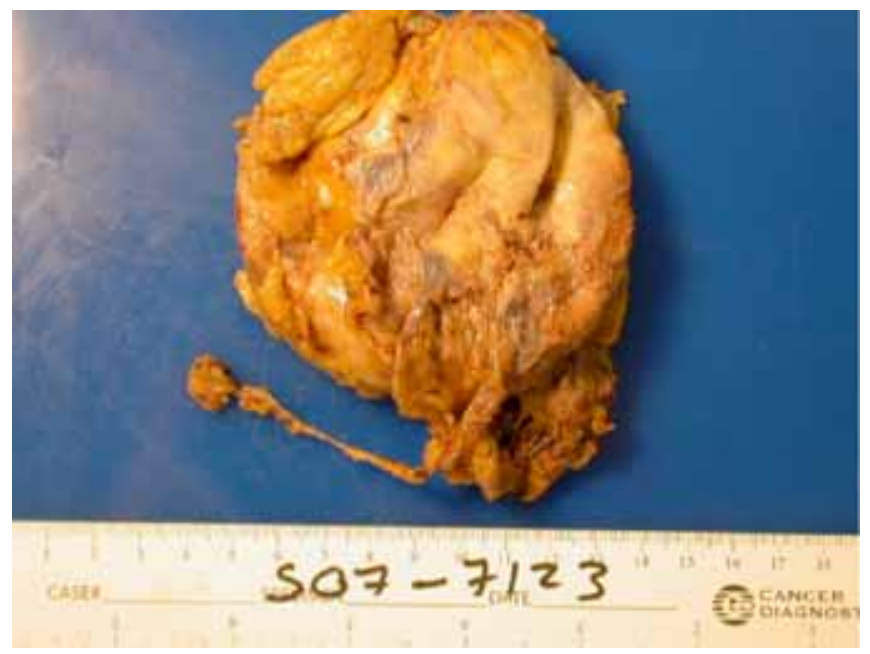

Fig. (4). The gross adrenal specimen; the cystic structure measuring $8 \mathrm{~cm} \times 8 \mathrm{~cm}$.

Microscopically, the wall of the cyst was composed of fibrous tissue and calcification without epithelial or endothelial lining (Figs. 5,6). The lumen of the cyst contained blood. Attenuated adrenal gland was present in the wall. No evidence of malignancy was found.
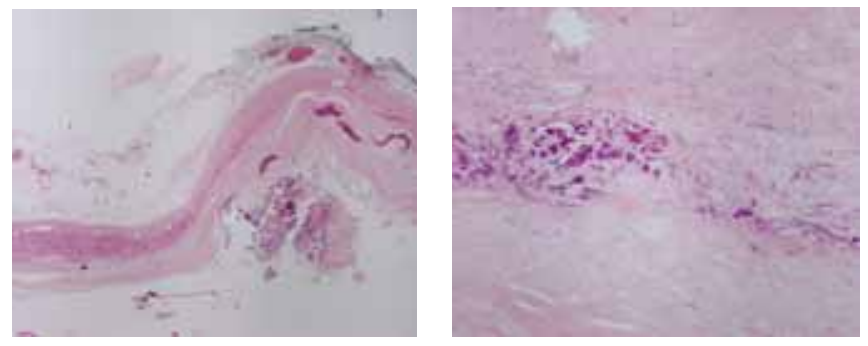

Figs. (5,6). Microscopy showing absence of epithelial or endothelial lining and the presents of fibrous tissue and calcification.

\section{DISCUSSION}

An adrenal pseudocyst was first described at autopsy by Greiseluis in 1670 [2]. It was described to be large enough to 'fill the left side of the abdomen displacing the diaphragm and spleen superiorly' and included a "rupture big enough to admit the fist".

The incidence of adrenal cysts at autopsy varies from $0.064 \%-0.18 \%$ [3] and in one study adrenal cysts were discovered incidentally in $0.02 \%$ of 12,000 CT scans [4]. Adrenal pseudocysts account for approximately $5.7 \%$ of all newly discovered incidentalomas [5]. An adrenal pseudocyst can be defined as a cystic lesions arising within the adrenal cortex or medulla, enclosed by a fibrous wall that is devoid of a recognisable lining [6]. Cysts are usually solitary lesions but are bilateral in about $10 \%$ of cases. Size varies widely and may correlate with the degree of malignancy. Asymptomatic, non-functional tumors smaller than $3 \mathrm{~cm}$ are less likely to be malignant than cysts larger than $6 \mathrm{~cm}$ [7].

Several types of adrenal cysts are recognized; pseudocysts, parasitic (hydatid) cysts, epithelial cysts, and endothe- lial cysts. $80 \%$ of adrenal cysts are thought to be either endothelial cysts or pseudocysts [8]. Endothelial cysts are most frequently lymphangiomatous in origin, whereas pseudocysts are believed to result from haemorrhage into or around a pathological or normal adrenal gland [9]. Adrenal pseudocysts have been reported in association with birth trauma and hemorrhagic disease as well as a wide variety of pathologic conditions such as acute trauma, crush injuries, burns, shock, toxaemia of pregnancy, syphilis, leukaemia, and incompatible blood transfusions [10].

Cysts occur from birth to 80 years, with a peak in the third to sixth decades. The female; male ratio is $2 ; 1$. The majority of adrenal cysts are asymptomatic but larger cysts can give rise to lumbar pain, vomiting, gastrointestinal discomfort or an abdominal mass [6]. Some may also present as an acute abdomen, usually due to intracystic haemorrhage, rupture, or infection [11].

The diagnosis of 'incidentalomas' is increasing in tandem with the increased utilization of abdominal ultrasonography and CT scans [4]. Imagining shows the position of the adrenal mass and either confirms or excludes multifocal lesions. $\mathrm{CT}$ is the gold standard imaging technique for adrenal masses. It can identify tumors as small as $1 \mathrm{~cm}$ with $100 \%$ sensitivity [3]. Calcifications may be seen in adrenal cysts, as in our case. In addition, the lack of enhancement of solid elements of a mass may help in the differential diagnosis of pseudocyst versus adrenal neoplasm [12]. Other modalities that have been used to evaluate cysts include ultrasonography and magnetic resonance imaging (MRI). Abdominal ultrasonography can detect adrenal masses larger than $2 \mathrm{~cm}$ in diameter and is inexpensive and low risk but it does not accurately define the size of an adrenal mass or its morphologic characteristics [13]. In contrast, MRI provides anatomical details and allows tissue characterization [13].

The above newly developed imaging techniques can detect and localize these lesions with high accuracy, but it remains difficult to differentiate malignancy, cortical adenoma, hyperplasia, or pheochromocytoma from benign cysts, such as in our case [14].

On CT, pseudocysts tend to be small, heterogeneously solid lesions with multiple internal fluid levels. Peripheral nodular calcification is more common in pseudocysts than in true cysts, and most pseudocysts have mural calcifications [15]. Benign lesions usually have a wall thickness of $3 \mathrm{~mm}$ or less whereas lesions with a wall thickness greater than $8 \mathrm{~mm}$ raise concern of malignancy [16]. The estimated risk of an adrenal cyst being malignant is 7\% [17].

Tissue diagnosis is usually favored preoperatively. Some authors recommend fine-needle aspiration (FNA) of adrenal cysts larger than $3.5 \mathrm{~cm}$ but whilst a normal tissue aspirate may exclude malignancy, a hemorrhagic aspirate may indicate malignancy or haemorrhage into a benign cyst [17]. Furthermore, several complications have been reported in association with FNA, the most important being seeding of a malignant tumor [18]. The most frequently seen complication is bleeding incorporating adrenal bleeds and haematomas. Other complications included pneumothorax, haemothorax, pancreatitis, and post-FNA pain [19]. In general, FNA is a sensitive and highly specific procedure for the evaluation of primary and metastatic malignancies involving 
the adrenal gland but is less useful in the workup of benign processes [20].

There is very sparse data regarding the management of incidentally discovered adrenal masses [19]. Surgical excision of these incidentilomas is usually the ultimate management and is usually indicated based on the following criteria; assessment of CT appearance, presence or absence of malignant disease elsewhere, endocrine functionality, and tumor size. The size (greatest diameter) at which an adrenal mass requires surgical excision has been variously described as $2.5,3.0,3.5,4.0,5.0$, and $6.0 \mathrm{~cm}[21-27]$. In a retrospective study, it is recommend that excision of all lesions $4.0 \mathrm{~cm}$ in size or greater, all hormonally active tumors, and those demonstrating interval growth, provided the patient is an acceptable surgical candidate [28]. If the criteria for a simple nonfunctional cyst are satisfied, the patient may be treated conservatively by monitoring with serial imaging or aspiration alone [6].

Initially, all adrenalectomies were performed via the transabdominal route. In the 1980s the posterior approach was adopted by many surgeons at first for small tumors, and later for large tumors, pheochromocytomas and metastases, because of a perceived decrease in surgical morbidity [19]. Laparoscopic adrenalectomy was first described by Gagner et al. in 1992 [29]. Initial indications were limited due to concerns about bleeding, the safety of removing pheochromocytomas, especially under carbon dioxide insufflation which theoretically might trigger a hypertensive crisis, the inability to do en bloc resections of invasive tumours, and the fear that removing cancers laparoscopically could result in metastatic seeding along the trocar port. As surgeons gained experience, indications for laparoscopic adrenalectomy expanded to include larger tumors, pheochromocytomas, and metastases [19]. Five laparoscopic approaches are described; anterior and lateral transperitoneal, lateral and posterior retroperitoneal, and thoracoscopic transdiaphragmatic [30-35]. Choosing between these approaches varies according to the location of the lesion, its size, patient morphology and most importantly the surgeon's experience. Anatomical knowledge, delicate tissue handling and meticulous haemostasis are the cornerstones of successful adrenal surgery.

Much controversy exists regarding indications for laparoscopic versus open adrenalectomy. Laparoscopic adrenalectomy is less invasive, has equivalent or better complication rates and, in terms of overall hospital expenses, is more costeffective [36-39] than open adrenalectomy. Laparoscopic surgery has been favored over the years as it's associated with less pain, better functional status, and earlier return to full activity [40]. Conversion rates of less than 3\%are reported and prior abdominal surgery is not an absolute contraindication to the laparoscopic approach [41]. It is suggested however that in patients with adrenal masses over $6 \mathrm{~cm}$ in size with stigmata of malignant disease, open adrenalectomy may reduce manipulation of the tumor whilst increasing the chances of ancomplete resection [42].

Laparoscopic conservative management of small adrenal cysts is safe and feasible. Laparoscopic decortication and marsupialization should be the preferred treatment option for symptomatic adrenal cysts. Laparoscopic partial adrenalectomy or a total adrenalectomy can be performed in cases of larger cysts, which compromise most of the adrenal gland [43].

\section{REFERENCES}

[1] Zucker, Karl A. 2001. Surgical Laparoscopy (2nd Addition). Philidelphia; Lippincott Williams and Wilkins; 2001.

[2] Doran AHG. Cystic tumour of the suprarenal body successfully removed by operation. Br Med J 1908; 1: 1558-63.

[3] Sroujreh AS, Farah GR, Haddad MJ, Abu-Khalaf MM. Adrenal cyst; diagnosis and treatment. Br J Urol 1990; 65; 570-5.

[4] Belldegrun A, Hussain S, Seltzer SE. Incidentally discovered mass of the adrenal gland. Surg Gynecol Obstet 1986; 163: 203-8.

[5] Mirilas P, Skandalakis JE. Benign anatomical mistakes; the correct anatomical term for the recurrent laryngeal nerve. Am Surg 2002; 68(1); 95-7.

[6] Mohan H, Aggarwal R, Tahlan A, Bawa AS, Ahluwalia M. Giant adrenal psuedocyst mimicking a malignant lesion. Can Med Assoc J 2003; 46: 6 .

[7] Fajardo R, Montalvo J, Velazquez D, et al. Correlation between radiologic and pathologic dimensions of adrenal masses. World $\mathrm{J}$ Surg 2004; 28(5); 494-7.

[8] Abeshouse GA, Goldstein RB, Abeshouse BS. Adrenal cysts; Review of the literature and report of 3 cases. J Urol 1959; 81; 711.

[9] Thomson AG, Jacobson SA. Pseudocyst of the Adrenal gland. Can Med Ass J 1966; 94: 90-91.

[10] Zupkner J. Adrenal cysts. Arch Pathol 1950; 50: 468.

[11] Sroujreh AS, Farah GR, Haddad MJ, Abu-Khalaf MM. Adrenal cyst; diagnosis and treatment. Br J Urol 1990; 65: 570-5.

[12] Wang LJ, Wong YC, Chen CJ, et al. Imaging spectrum of adrenal pseudocysts on CT. Eur Radiol 2003; 13(3): 531-5.

[13] Case records of the Massachusetts General Hospital. Weekly clinicopathological exercises. Case 15-1992. A 23-year-old woman with a painful mass in the right adrenal region. N Engl J Med 1992; 326(15); 1008-15.

[14] Chew SP, Sin R, Teoh TA, Low CH. Hemorrhage into nonfunctioning adrenal cysts; Report of two cases and review of the literature. Ann Acad Med Singap 1999; 28; 863-6.

[15] Chang G, Sharobeim A, Ozeata M, et al. Incidental Adrenal Pseudocyst. Surg Rounds 2006.

[16] Rozenblit A, Morehouse HT, Amis ES Jr. Cystic adrenal lesions; CT features. Radiology 1996; 201(2): 541-8.

[17] Neri LM, Nance FC. Management of adrenal cysts. Am Surg 1999; 65(2): 151-63.

[18] Voravud N, Shin DM, Dekmezian RH, Dimery I, Lee JS, Hong WK. Implantation metastasis of carcinoma after percutaneous fineneedle aspiration biopsy. Chest 1992; 102: 313-5.

[19] Lau J, Balk E, Rothberg M, et al. Management of clinically inapparent adrenal mass (summary). Evid Rep Techno Assess 2002; 56: $1-5$.

[20] Wadih GE, Nance KV, Silverman JF. Fine-needle aspiration cytology of the adrenal gland. Fifty biopsies in 48 patients. Arch Pathol Lab Med 1992; 116(8): 841-6.

[21] Seddon JM, Baranetsky N, Van Boxel PJ. Adrenal "incidentaloma,'“; Need for surgery. Urology 1985; 25: 1-7.

[22] Prinz RA, Brooks MH, Churchill R, et al. Incidental asymptomatic adrenal masses detected by computed tomographic scanning; is operation required? JAMA 1982; 248: 701-4.

[23] Staren ED, Prinz RA. Selection of patients with adrenal incidentalomas for operation. Surg Clin North Am 1995; 75: 499-509.

[24] O'Leary TJ, Ooi TC. The adrenal incidentaloma. Can J Surg 1986; 29: 6.

[25] Mitnick JS, Bosniak MA, Megibow AJ, Naidich DP. Nonfunctioning adrenal adenomas discovered incidentally on computed tomography. Radiology 1983; 148: 495.

[26] Gajraj H, Young AE. Adrenal incidentaloma. Br J Surg 1993; 80: 422-6.

[27] Thompson NW, Cheung PSY. Diagnosis and treatment of functioning and nonfunctioning adrenocortical neoplasms including incidentalomas. Surg Clin North Am 1987; 67: 423-36.

[28] Herrera MF, Grant CS, van Heerden JA, Sheedy PF, II, Ilstrup DM. Incidentally discovered adrenal tumors; an institutional perspective. Surgery 1991; 110: 1014-21.

[29] Gagner M, Lacroix A, Bolte E. Laparoscopic adrenalectomy in Cushing's syndrome and pheochromocytoma. N Engl J Med 1992; $327 ; 1033$. 
[30] Suzuki K, Kageyama S, Hirano Y, Ushiyama T, Rajamahanty S, Fujita K. Comparison of 3 surgical approaches to laparoscopic adrenalectomy; a nonrandomized, background matched analysis. J Urol 2001; 166; 437-43.

[31] Soble JJ, Gill IS. Needlescopic urology; incorporating 2-mm instruments in laparoscopic surgery. Urology 1998; 52: 187-94.

[32] Meraney AM, Gill IS, Hsu TH, Sung GT. Thoracoscopic transdiaphragmatic nephrectomy; feasibility study. Urology 2000; 55; 443-47.

[33] Gasman D, Droupy S, Koutani A, et al. Laparoscopic adrenalectomy; the retroperitoneal approach. J Urol 1998; 159; 1816-1820.

[34] Sung GT, Hsu TH, Gill IS. Retroperitoneoscopic adrenalectomy; lateral approach. J Endourol 2001; 15; 505-11.

[35] Gill IS, Meraney AM, Thomas JC, Sung GT, Novick AC, Lieberman I. Thoracoscopic transdiaphragmatic adrenalectomy; the initial experience. J Urol 2001; 165; 1875-81.

[36] Thompson GB, Grant CS, van Heerden JA, et al. Laparoscopic versus open posterior adrenalectomy; a case-control study of 100 patients. Surgery 1997; 122; 1132-36.
[37]

Schell SR, Talamini MA, Udelsman R. Laparoscopic adrenalectomy for non malignant disease; improved safety, morbidity and costeffectiveness. Surg Endosc 1999; 13; 30-34.

[38] Hobart MG, Gill IS, Schweizer D, Bravo EL. Financial analysis of needlescopic versus open adrenalectomy. J Urol 1999; 162; 1264-7.

[39] Imai T, Kikumori T, Ohiwa M, Mase T, Funahashi H. A casecontrolled study of laparoscopic compared with open lateral adrenalectomy. Am J Surg 1999; 178; 50-53.

[40] Norton J. Laparoscopic versus open adrenalectomy. J Clin Endocrinol Metab 1998; 83; 3048.

[41] Gagner M, Pomp A, Heniford BT, Pharand D, Lacroix A. Laparoscopic adrenalectomy; lessons learned from 100 consecutive procedures. Ann Surg 1997; 226(3); 238-47.

[42] Brunt LM, Doherty GM, Norton JA, Soper NJ, Quasebarth MA, Moley JF. Laparoscopic adrenalectomy compared to open adrenalectomy for benign adrenal neoplasms. J M Col Surg 1996; 183; 110

[43] Castillo OA, Litvak JP, Kerkebe M, And Urena RD. Laparoscopic Management of Symptomatic and Large Adrenal Cysts. J Urology $2005 ; 173 ; 915-7$.

(C) Aloraifi et al.; Licensee Bentham Open.

This is an open access article distributed under the terms of the Creative Commons Attribution License (http: //creativecommons.org/licenses/by/2.5/), which permits unrestrictive use, distribution, and reproduction in any medium, provided the original work is properly cited. 